\title{
Extracorporeal Treatment in the Management of Acute Poisoning: What an Intensivist Should Know?
}

\author{
Vijoy Kumar Jha, K. V. Padmaprakash'1 \\ Department of Nephrology, Command Hospital Air Force Bangalore, Bengaluru, Karnataka, 'Department of Medicine, INHS Kalyani, Visakhapatnam, Andhra Pradesh, India
}

\section{Abstract}

Extracorporeal treatment (ECTR) represents a treatment modality promoting removal of endogenous or exogenous poisons and supporting or temporarily replacing a vital organ. This article aims to provide a brief overview of the technical aspects and the potential indications and limitations of the different ECTRs, highlighting the important characteristics of poison amenable to ECTR and the most appropriate prescriptions used in the setting of acute poisoning. The various principles that govern poison elimination by ECTR (diffusion, convection, adsorption, and centrifugation) and how components of the ECTR can be adjusted to maximize clearance have also being discussed.

Keywords: End-stage kidney disease, extracorporeal treatment, hemoperfusion, intermittent hemodialysis

\section{INTRODUCTION}

Majority of exposures due to poisonous substances need supportive care only. Extracorporeal treatments (ECTRs) are required in $0.1 \%$ of intoxications. ${ }^{[1]}$ ECTR represents a heterogeneous group of treatments promoting removal of endogenous or exogenous poisons, supporting or temporarily replacing a vital organ, or a combination of these two. Use of hemodialysis for the elimination of toxic substances predates its use for end-stage kidney disease (ESKD) by many years. The first successful in vivo experiment with hemodialysis was carried out in 1913, and removal of salicylates from poisoned animals was demonstrated. ${ }^{[2]}$ Yet after so many years, the application of ECTR in the management of poisoned patients remains debatable. A multidisciplinary and multinational collaborative known as Extracorporeal treatment in poisoning (EXTRIP) workgroup has been established with the aim to clarify the role of ECTRs in clinical practice through the development of evidence- and expert opinion-based recommendations. ${ }^{[3]}$

\section{Principles and Methods of Toxic Substance ReMOVAL}

The various methods available for toxic substance removal by ECTR are diffusion, convection, adsorption, and centrifugation [Table 1].

\begin{tabular}{|l|l|}
\hline \multicolumn{2}{|c|}{ Access this article online } \\
\hline Quick Response Code: & Website: \\
\hline & www.ijccm.org \\
\cline { 2 - 2 } & \\
\hline
\end{tabular}

\section{Diffusion-hemodialysis}

In intermittent hemodialysis (IHD), the movement of particles (solutes) is driven by diffusion, i.e., a concentration gradient from one compartment to another through a semi-permeable membrane. Characteristics influencing solute clearance through diffusion include the magnitude of the concentration gradient (blood and dialysate flow rates), duration of therapy, and the filter composition. The maximum possible clearance of the solute corresponds to the slower of the two flows ( $\mathrm{Qb}$ - blood flow rate and Qd - dialysate flow rate), which will be the rate-limiting step. The clearance of small water-soluble solutes will exceed that of larger particles because the mobility of the solute between the compartments influences clearance. Targeting a $\mathrm{Qd} / \mathrm{Qb}$ ratio $>2.5: 1$ may be ensured so that clearance of small molecules is not restricted by dialysate flow. ${ }^{[4]}$ Countercurrent direction of dialysate flow provides $20 \%-30 \%$ better clearances for small molecules than a concurrent direction of flow. Increasing $\mathrm{Qb}$ also increases the clearance of middle molecules such as vancomycin when a high-flux filter is used. Similar results were shown

Address for correspondence: Dr. Vijoy Kumar Jha, Physician and Nephrologist, Department of Nephrology, Command Hospital Air Force Bangalore, Bengaluru - 560 007, Karnataka, India. E-mail: vkjhamd@gmail.com, vkjhamd@rediffmail.com

This is an open access journal, and articles are distributed under the terms of the Creative Commons Attribution-NonCommercial-ShareAlike 4.0 License, which allows others to remix, tweak, and build upon the work non-commercially, as long as appropriate credit is given and the new creations are licensed under the identical terms.

For reprints contact: reprints@medknow.com

How to cite this article: Jha VK, Padmaprakash KV. Extracorporeal treatment in the management of acute poisoning: What an intensivist should know? Indian J Crit Care Med 2018;22:862-9. 


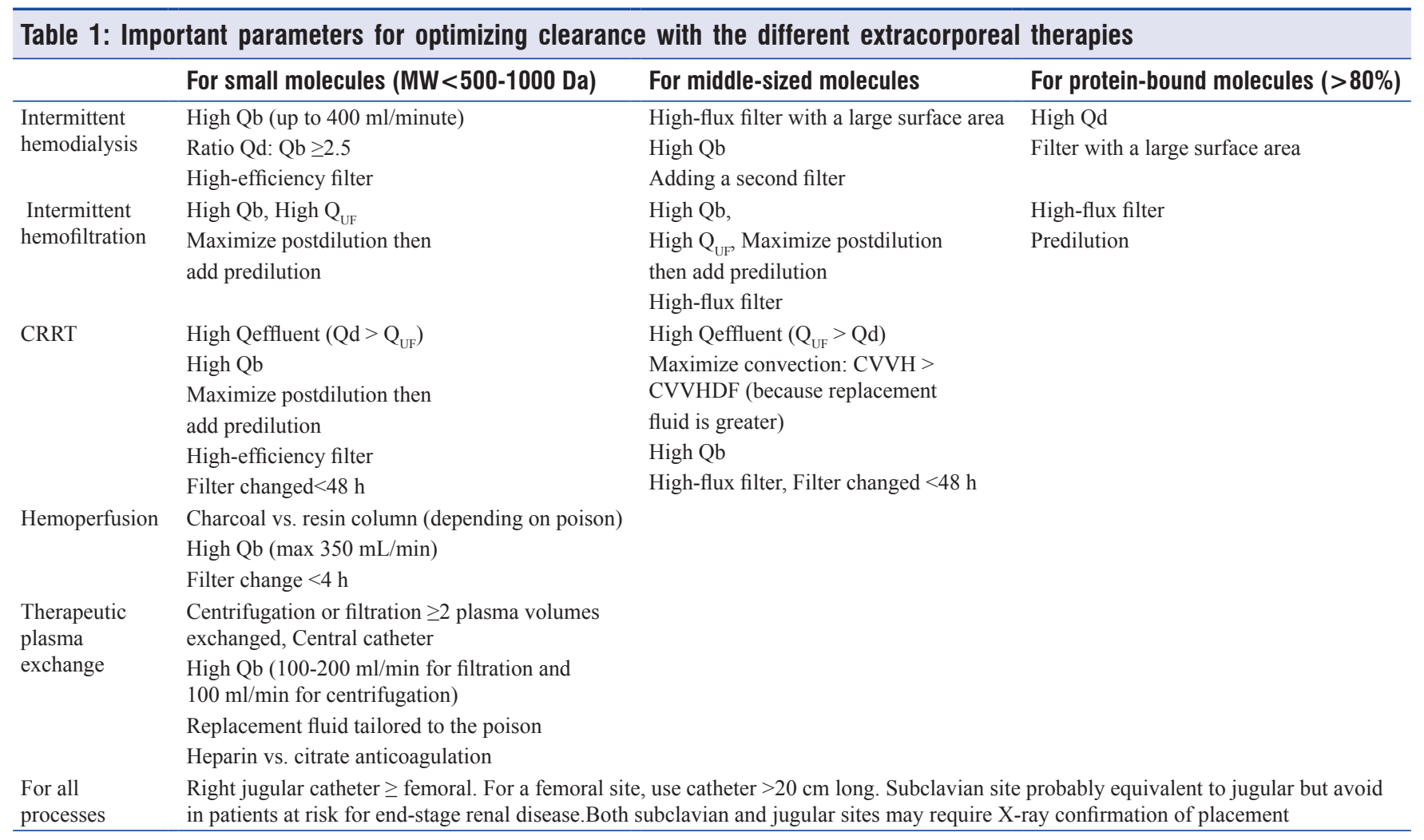

in poisonings due to phenobarbital, lithium, and phenytoin, where clearance plateaued when $\mathrm{Qb}$ exceeded approximately $300 \mathrm{ml} / \mathrm{min}$ in the context of Qd $500 \mathrm{ml} / \mathrm{min}$. Increases in Qb and Qd are associated with a lesser increase in the clearance of middle-sized molecules by diffusion, such as Vitamin B12 and $\beta 2$-microglobulin with no significant change for larger molecules such as dextran. ${ }^{[5]} \mathrm{Qb}$ is usually limited to $<400 \mathrm{ml} / \mathrm{min}$ when using an intravascular catheter due to blood turbulence and resistance in the tubing. Augmenting Qd increases clearance by approximately 10\%-20\% for small-molecular-weight (MW) molecules but does not affect the clearance of larger molecules. ${ }^{[6,7]}$ There is an improved clearance of larger MW solutes relative to small MW solutes with high-flux membranes. The simultaneous use of more than one filter, or even two distinct circuits, can increase clearance. ${ }^{[8]}$ The benefit of either configuration (series or parallel) provides an incremental clearance gain of approximately $5 \%-7 \%$ due to the effect of increasing the surface area for filtration and improving clearance of small molecules, particularly in very large sized patients. ${ }^{[8]}$

Albumin dialysis may facilitate the clearance of highly protein-bound toxins because the unbound fraction diffuses into the dialysate side where it binds to albumin and is trapped. There will be a protein-binding disequilibrium on the blood side and more drug would become unbound and cross the membrane to be cleared. ${ }^{[9]} \mathrm{A}$ favorable impact of larger albumin concentration on the clearance of protein-bound toxins has been observed for diazepam, valproic acid, and carbamazepine.
IHD is frequently available, least expensive with fewer complications, and quickest to implement when compared to hemoperfusion, therapeutic plasma exchange (TPE), or albumin dialysis. The ability of IHD to treat concomitant metabolic disorders and its significant clearance capacity for a wide spectrum of toxic substances ${ }^{[10]}$ are the main reasons why IHD remains the treatment of choice for most poisonings. The duration of IHD in poisoning can be prolonged depending on the clinical setting and nursing availability. The dialysate is usually tailored to the patient requiring dialysis as these poisoned patients may have a very different metabolic profile than one with renal failure.

\section{Convection-hemofiltration}

In hemofiltration (HF), poison and solvent are simultaneously removed by convection and replaced by a physiological solution, whereas intermittent hemodiafiltration (HDF) combines convection and diffusion. In convection, there is a movement of solvent and solutes according to a pressure gradient (solvent drag) and, to maintain volume homeostasis, an ultrapure replacement fluid is reinfused to the patient. Convection efficacy is mainly dependent on the size of the dialyzer membrane pores. Convection allows removal of poisons as large as 25,000 Da. As the large majority of known poisons have a low MW ( $<2000 \mathrm{Da})$, HF would not seem to be more advantageous than HD in the majority of poisonings. Factors influencing solute clearance during convection include $\mathrm{Qb}$, ultrafiltration rate $\left(\mathrm{Q}_{\mathrm{UF}}\right)$, the site of fluid replacement, and the type of hemofilter. Solute clearance increases when either $\mathrm{Qb}$ or $\mathrm{Q}_{\mathrm{UF}}$ is increased. The difference in clearances 
between convection and diffusion increases as the solute's $\mathrm{MW}$ increases. Increases in $\mathrm{Qb}$ have a more limited effect on the removal of larger molecules such as $\beta 2$-microglobulin compared with smaller molecules. ${ }^{[11]}$ Postdilution HF is associated with an increased risk of clotting of the filter and requires anticoagulation, which is not essential in predilution. ${ }^{[12]}$ Clearances of middle-sized solutes up to 10,000 Da are higher with a high-flux membrane and become negligible with an MW $>20,000 \mathrm{Da}$. Another advantage of a larger filter surface area is that it can withstand greater transmembrane pressures for a longer period of time, ${ }^{[6]}$ allowing higher $\mathrm{Qb}$ and convective fluxes across the membrane. Protein-leaking membranes, named as high cutoff (HCO) or "superflux" membranes, are highly permeable membranes with improved removal of protein-bound solutes and large-sized unbound solutes at the expense of a heavier albumin loss. ${ }^{[13]}$ Protein-leaking membranes can be used for poisons that are highly protein bound, considering the fact that albumin loss likely has negligible clinical significance when these filters are used for a limited number of sessions. ${ }^{[14]}$ Diffusion and convection have a comparable effect on the clearance of smaller MW molecules $(<500-1000 \mathrm{Da})$, while convection provides much higher clearances for middle MW molecules (1000-10,000 Da) compared with diffusion. Therefore, the clearance of small MW molecules can be enhanced by adding convection to diffusion, thereby increasing the total effluent rate. ${ }^{[15]}$ However, the opposite is not true for middle MW molecules. In HDF, ultrafiltration and predilution may have a negative impact on transmembrane concentration gradients; however, the addition of convection may improve the clearance of some solutes such as phosphorus. ${ }^{[16]}$

\section{Continuous Renal Replacement Therapy/ Sustained Low-Efficiency Dialysis}

Continuous renal replacement therapies (CRRTs) are often used in the critical care setting to manage acute kidney injury, especially in fluid overloaded, hemodynamically unstable patients. Poison clearance with CRRT is $50 \%-80 \%$ less than that obtained with intermittent modalities because of lower blood and/or effluent flow rates. ${ }^{[17]}$ For example, clearances for methanol are usually limited to under $50 \mathrm{ml} / \mathrm{min}$ with CRRT, while they can surpass $200 \mathrm{ml} / \mathrm{min}$ with IHD. CRRT following an HD session is used by some clinicians to minimize a re-increase in poison concentration, or rebound. Sustained low-efficiency dialysis (SLED) is a hybrid technique usually provided as a prolonged treatment using both reduced Qd and $\mathrm{Qb}$ and differs from CRRT in three areas namely shorter duration, higher Qd than CRRT, and can be administered using the same equipment as standard IHD. Although SLED uses a higher Qd than CRRT, the small solute clearance between these two modalities is reportedly similar. ${ }^{[10]}$ The modeled clearance of middle and large solutes during CRRT is greater than that during SLED, likely due to the extended duration and additional convective clearance in CRRT. ${ }^{[18]}$ In lithium poisoning, following dialysis, poison may transfer from the site of central nervous system (CNS) toxicity to a relatively more benign vascular compartment ${ }^{[19]}$ and may further present an added opportunity for extracorporeal removal. When poison removal is urgent, SLED and CRRT are not the treatments of choice unless no other method is available or ultrafiltration is needed in an unstable patient. ${ }^{[20]}$

\section{Adsorption/hemoperfusion}

Adsorption is a process by which particles located in the blood compartment bind reversibly or irreversibly to the surface of a column (or sorbent). Its contribution to total clearance is variable, and cannot be easily predicted by considering the type of filter and/or the MW of the poison. ${ }^{[2]}$ It has a minor effect on clearance compared with convection and diffusion, is more pronounced for middle and large MW molecules, and largely occurs within the $1^{\text {st }} \mathrm{h}$ after a filter change. During HP, whole blood passes through a charcoal-coated cartridge onto which the poison can be adsorbed. ${ }^{[22]}$ However, HP requires greater systemic anticoagulation than do other ECTRs, and the prescribed blood flow must not exceed $350 \mathrm{ml} / \mathrm{min}$ to avoid the risk of hemolysis. ${ }^{[23]} \mathrm{HP}$ also nonselectively adsorbs platelets, white blood cells, calcium, and glucose. ${ }^{[24]}$ Further, a charcoal cartridge costs ten times more than a high-efficiency dialyzer, does not bind all poisons (e.g., alcohols and certain metals), and needs to be replaced every $2 \mathrm{~h}$ because of cartridge saturation, which decreases poison clearance. ${ }^{[25]}$

\section{Centrifugation-therapeutic plasma exchange}

Centrifugation separates the whole blood into various components according to their specific gravity. The most important factor influencing clearance with centrifugation is the total volume of plasma exchanged per session. In the treatment of a poisoned patient, the American Society for Apheresis guidelines recommend an exchange volume of one to two total plasma volumes per day until clinical symptoms have decreased and the release of toxin from tissues is no longer significant. ${ }^{[2]}$ Poison clearance during these techniques cannot exceed $50 \mathrm{ml} / \mathrm{min}$. Their role in the treatment of acute poisoning is only considered for tightly and/or highly protein-bound poisons ( $>95 \%)$ or poisons with MW over 50,000 Da such as monoclonal antibodies, ${ }^{[27]}$ but even then, the benefit is debatable considering the complications of these techniques including bleeding, hypocalcemia, and hypersensitivity reactions. The clearance capacity of TPE is much lower than that of IHD, IHF, or HP. ${ }^{[28]}$ There is some support for it in exposures to the mushroom Amanita Phalloides, thyroxine, vincristine, and cisplatin. It should only be considered when alternative ECTRs are useless or unavailable while taking into account its higher cost and complication rates.

\section{Peritoneal dialysis}

The use of peritoneal dialysis (PD) is infrequent in poisoning, due to its limited clearance capacity. For example, clearances for theophylline are $10 \mathrm{ml} / \mathrm{min}$ with PD compared to $85 \mathrm{ml} / \mathrm{min}$ with IHD. ${ }^{[29]}$

\section{Exchange transfusion}

In toxicology, exchange transfusion is seldom used but has been described in poisoning with xenobiotics highly bound 
to erythrocytes such as cyclosporine or tacrolimus and to treat methemoglobinemia induced by a toxic exposure (e.g., propranolol, aniline, dapsone, and sodium nitrite). Exchange transfusion has the advantage of being simpler to use in infants and has been tried in that population for poisonings to salicylates, theophylline, and barbiturates. ${ }^{[30]}$

\section{Cerebrospinal fluid exchange}

Cerebrospinal fluid (CSF) exchange is occasionally performed in patients with life-threatening neurological symptoms to certain poisons. The CSF is drained passively via a ventricular catheter and replaced by a sterile solution containing albumin and sodium chloride into the lumbar subarachnoid space.

\section{Extracorporeal life support}

Extracorporeal life support includes extracorporeal membrane oxygenation (ECMO), emergency cardiopulmonary bypass, intraaortic balloon pumps, and left ventricular assist devices. ECMO is increasingly used as a bridge to recovery in clinically refractory patients with cardiovascular and/or pulmonary failure not responding to conventional medical therapies. ${ }^{[30]}$ Extracorporeal liver-assist devices remain occasionally used to support liver function in poison-induced hepatotoxicity. ${ }^{[31]}$

\section{Risk Assessment of Patients and Consideration of Extracorporeal Treatment [Table 2]}

The majority of poisoned patients who present to the emergency department are successfully treated only with supportive care and recover without any complication. ECTR is typically reserved for the small subset of patients who are likely to suffer life-threatening toxicity, prolonged admission in the intensive care unit with coma and mechanical ventilation (e.g., barbiturate overdose), a high likelihood of permanent disability (e.g., methanol overdose), or develop toxicity despite standard supportive measures. ECTR is usually not indicated if the poison has limited intrinsic toxicity and if the

\section{Table 2: Indications of extracorporeal treatment}

Exposure to the poison likely to cause serious morbidity and mortality

Poison toxicity unlikely to be prevented or reversed by an antidote

Poison toxicity unlikely to be minimized by treatments that prevent

absorption and/or enhance elimination

Poison's endogenous clearance $<4 \mathrm{ml} / \mathrm{min} / \mathrm{kg}$

Volume of distribution $<1-2 \mathrm{~L} / \mathrm{kg}$

\section{Table 3: Extracorporeal treatment options}

$>95 \%$ of poison is protein bound at current concentration - therapeutic plasma exchange

$80 \%-95 \%$ of poison is protein bound - hemoperfusion

$<80 \%$ of poison is protein bound

Poison's MW - 1500 Da - high-flux HD

Poison's MW - 15-20,000 Da - hemofiltration

Poison's MW - 20-50,000 Da - high cutoff/middle cutoff HD, hemofiltration Poison's MW - >50,000 Da - therapeutic plasma exchange

MW: Molecular weight; HD: Hemodialysis estimated threshold dose (in $\mathrm{mg} / \mathrm{kg}$ ) or plasma concentration is not associated with toxicity. ${ }^{[32]}$ Apart from antidotes which can prevent, limit, or reverse toxicity, several therapies may either prevent absorption (gastric emptying, activated charcoal, or whole-bowel irrigation) or enhance elimination (multiple dose-activated charcoal or urinary alkalinization). When these alternative treatments are either not available or unlikely to be sufficient, timely consideration for ECTR is indicated if the poison is considered dialyzable.

\section{Characteristics of Poisons Treated with Extracorporeal Treatment [Table 3]}

Dialysability of a poison depends on its physicochemical and toxicokinetic properties. The primary determinants of poison removal by ECTR are the MW, the volume of distribution (VD), hydrophilicity and lipophilicity, protein and tissue binding, and endogenous clearance. The low MW poisons are easily dialyzable. High-efficiency high-flux dialyzers with diffusive modalities are capable of clearing poisons in the middle MW range $(<15,000 \mathrm{Da})$. Convective modalities such as HF and HDF allow clearance of solutes approaching 25,000 Da. New HCO and middle-cutoff membranes may remove poisons up to 50,000 $\mathrm{Da} \cdot{ }^{[33,34]}$ ECTR only clears poisons from the intravascular compartment, so poisons exhibiting a smaller $\mathrm{VD}(<1 \mathrm{~L} / \mathrm{kg})$ are easily removed by ECTR. Early preemptive initiation of ECTR during the absorption and distribution phases may promote the removal of a significant amount of poisons with a large VD. Hydrophilic poisons distribute primarily in total body water, exhibit a smaller VD, and are more readily removed by ECTR, whereas lipophilic poisons distribute throughout extravascular tissues, especially adipose tissue, leading to a large VD. The degree of plasma protein and tissue binding of a poison is inversely related to its extracorporeal clearance because only unbound poison (free fraction) is removed by most ECTRs. Poisons that are $>80 \%$ protein bound are poorly removed by hemodialysis. Some drugs (salicylates and valproic acid) have high protein-binding ability at therapeutic concentrations but saturate at high plasma concentrations, increasing the free concentration and rendering them more easily removed by ECTR ${ }^{[35]}$ If endogenous clearance is high, then an ECTR is unlikely to benefit unless there is impaired kidney function. ${ }^{[36]}$ Indications other than poison removal (e.g., acute kidney injury or acidemia) may be the reason for ECTR. ${ }^{[37,38]}$

\section{Dialysis Prescriptions to Maximize Clearance [TABLE 1]}

As earlier explained, the dialysis prescriptions to maximize extracorporeal elimination are higher blood flow, higher dialysate flow, higher ultrafiltration rate, postfilter replacement with HF, larger filter or kidney (surface area and flux), and longer duration. ${ }^{[39]}$ The solute clearance cannot exceed the lowest flow rate i.e. plasma flow rate in case of hemodialysis and effluent flow rate in case of CRRT. An increase in effective 
flow rates and/or filter size will produce an approximately proportional increase in solute clearance at lower flows, but there is a smaller incremental increase in clearance at higher flows with diffusion than with convection techniques. ${ }^{[39]}$

\section{What to be monitored during extracorporeal treatment for the poisoned patient?}

Initiation of an ECTR during the absorption phase is beneficial because a larger proportion of the poison in the intravascular compartment is available for removal by ECTR during this time. The duration of ECTR should be tailored to the clinical situation, so the "routine" 4-h treatment reserved for patients with ESKD should be challenged in the treatment of a poisoned patient. Treatment duration can be increased for $>10 \mathrm{~h}$, as needed, for example, with dabigatran, ethylene glycol, and methanol poisoning. A precise estimate of the duration of ECTR to achieve a target concentration is possible when the elimination half-life is calculated using serial plasma concentrations obtained during treatment, allowing for individualized decision-making like in ethylene glycol and other poisons ${ }^{[40]}$ A rebound in the plasma concentration may be anticipated after completion of the ECTR, particularly in the case of hydrophilic drugs taken for chronic therapy, such as dabigatran and lithium toxicity ${ }^{[41,42]}$ However, rebound that occurs from ongoing absorption can produce much higher concentrations, resulting in clinical toxicity. The typical dialysis solutions containing high bicarbonate, low potassium, and absent phosphate concentrations, which may be harmful, particularly with prolonged treatments and poisoned patients, may even require supplemental electrolytes, such as phosphate. Anticoagulation should be decided with caution because some poisons are associated with an increased risk of bleeding-for example, methanol-associated intracerebral hemorrhage or poisons inducing systemic anticoagulation. In both cases, regional citrate or anticoagulant-free strategies are preferred. Predilution IHDF can be performed without anticoagulation, whereas postdilution IHDF usually requires anticoagulation because of increased viscosity of blood in the hemofilter.

\section{Extracorporeal treatment in poisoning workgroup}

A group of experts in 2010 met to discuss the terms of reference to develop guidelines on the use of ECTR in severe poisoning based on systematic reviews of the literature combined with multidisciplinary expert consensus. ${ }^{[3]}$ This workgroup reviewed several poisons and provided recommendations that include specific indications for ECTR [Table 4]. The intent of the ECTR may be considered either as "therapeutic" as in lithium-induced neurotoxicity or "prophylactic" as in high salicylate concentration in a minimally symptomatic patient.
Recommendations for salicylates, lithium, theophylline, valproate, or thallium provide indications for ECTR based on specific cutoff plasma concentrations irrespective of the signs or symptoms. ${ }^{[43]}$ ECTR mainly reduces the overall cost of antidote therapy and length of hospital stay in the case of early methanol poisoning prior to the development of acidosis. The workgroup also provided criteria for ECTR cessation, which usually depends on a noticeable clinical improvement of toxic symptoms, targets of surrogate parameters of toxicity (e.g., $\mathrm{pH}$ or lactate), or a specific poison concentration below which toxicity is no longer expected. Other recommendations include the preferred type of ECTR for every reviewed poison (favoring intermittent HD in all circumstances) and specific miscellaneous recommendations regarding anticoagulation, special populations, and antidotal dose. The executive summaries of all EXTRIP recommendations are published at http:// www.extrip-workgroup.org/recommendations. For tricyclic antidepressants and digoxin, the adverse effects of ECTR outweigh any potential benefit of ECTR, and thus the recommendations are not to perform ECTR. ${ }^{[44,45]}$

\section{Management of Acute Poisoning with Some Selected Agents and Preferred Extracorporeal Treatment Techniques [Table 5]}

Acute poisoning with any agents require initial stabilization of patients, administration of agent-specific antidotes if available, and ECRTs if indicated as mentioned in detail earlier. In poisoning with acetaminophen, activated charcoal should be given to patients presenting within $4 \mathrm{~h}$ of ingestion. $\mathrm{N}$-acetylcysteine (NAC) orally or intravenously (IV) should be given if the likelihood of toxicity is high or serum acetaminophen levels are above $150 \mathrm{mg} / \mathrm{L}$. Although acetaminophen is easily removed by dialysis or hemoperfusion, NAC remains the treatment of choice. Aspirin is well removed by hemodialysis due to its low VD. In barbiturates, poison removal with hemodialysis using a synthetic membrane dialysis equals that of hemoperfusion and should be contemplated in case of prolonged coma in spite of activated charcoal and urinary alkalinization. ${ }^{[46]}$ In the case of paraquat poisoning, survival depends on the amount ingested and plasma level with respect to the time of ingestion. Plasma level above $3 \mathrm{mg} / \mathrm{L}$ is usually fatal regardless of when it is measured. ${ }^{[4]}$ Repeated or continuous hemoperfusion may be needed. Hemodialysis should be used in the first $24 \mathrm{~h}$ after poisoning. Use of antioxidants is investigational. ${ }^{[48]}$

Lithium (Li) is very well removed by hemodialysis. Hemodialysis should be considered when serum lithium level is $>3.5 \mathrm{mmol} / \mathrm{L}$, serum $\mathrm{Li}$ is $>2.5 \mathrm{mmol} / \mathrm{L}$ in patients

Table 4: Level of recommendations as reviewed by Extracorporeal treatment in poisoning (EXTRIP) workgroup

\begin{tabular}{llll}
\hline Recommendation against & Neutral & Suggestion for & Recommendation for \\
\hline $\begin{array}{l}\text { Digoxin, tricyclic } \\
\text { antidepressant }\end{array}$ & Phenytoin & $\begin{array}{l}\text { Acetaminophen } \\
\text { Carbamazepine }\end{array}$ & Barbiturates, lithium, methanol, metformin, salicylates, thallium, theophylline, valproate \\
\hline
\end{tabular}




\begin{tabular}{|c|c|c|c|}
\hline Agents & Initial management & $\begin{array}{l}\text { Preferred technique/ } \\
\text { recommendations }\end{array}$ & Remarks \\
\hline $\begin{array}{l}\text { Acetaminophen (MW } \\
151 \mathrm{Da})\end{array}$ & $\begin{array}{l}\text { N-Acetylcysteine therapy. } \\
\text { Can be recommended even } \\
\text { after } 24 \mathrm{~h}\end{array}$ & HD or hemoperfusion & Moderately water soluble and minimally protein bound \\
\hline Aspirin (MW $180 \mathrm{Da})$ & MDAC. Urine alkalinization & $\begin{array}{l}\text { HD when serum level } \\
>90 \mathrm{mg} / \mathrm{dl} \text { or there is } \\
\text { evidence of academia, } \\
\text { neurological involvement, } \\
\text { or noncardiogenic } \\
\text { pulmonary edema }\end{array}$ & VD of only $0.15 \mathrm{~L} / \mathrm{kg}$. The drug is about $50 \%$ protein bound \\
\hline Digoxin (MW $781 \mathrm{Da})$ & $\begin{array}{l}\text { Correction of } \\
\text { dyselectrolytemia, alkalosis, } \\
\text { and oral activated charcoal } \\
\text { administration }\end{array}$ & $\begin{array}{l}\text { Hemoperfusion or } \\
\text { plasmapheresis. In dialysis } \\
\text { patients - Fab therapy }\end{array}$ & $\begin{array}{l}\text { VD of digoxin is large }(8 \mathrm{~L} / \mathrm{kg}) \text { and the drug is } 25 \% \text { protein } \\
\text { bound. Only } 5 \% \text { of body load is removed by HD }\end{array}$ \\
\hline $\begin{array}{l}\text { Lithium carbonate } \\
\text { (MW7 Da) }\end{array}$ & $\begin{array}{l}\text { Prompt rehydration. } \\
\text { Stop diuretics. Sodium } \\
\text { polystyrene sulphonate }\end{array}$ & $\begin{array}{l}\text { HD with high-clearance } \\
\text { dialyzer for } 8-12 \mathrm{~h} \text { as } \\
\text { lithium may rebind. } \\
\text { Prolonged continuous } \\
\text { hemodiafiltration reduces } \\
\text { rebound of lithium } \\
\text { posttreatment }\end{array}$ & $\begin{array}{l}0 \% \text { protein bound with } \mathrm{VD} \text { of } 0.8 \mathrm{~L} / \mathrm{kg} \text {. Repeated dialysis } \\
\text { may be needed until serum } \mathrm{Li} \text { levels remain below } 1.0 \\
\mathrm{mmol} / \mathrm{L} \text { for } 6-8 \mathrm{~h} \text { after dialysis }\end{array}$ \\
\hline Paraquat (MW $257 \mathrm{Da})$ & $\begin{array}{l}\text { Gastric lavage-activated } \\
\text { charcoal or Fuller's earth } \\
\text { with cathartic }\end{array}$ & Hemoperfusion & $\begin{array}{l}\text { Repeated or continuous hemoperfusion to maintain plasma } \\
\text { levels }<0.1 \mathrm{mg} / \mathrm{L} \text {. Large VD and slow intercompartmental } \\
\text { transfer rate }\end{array}$ \\
\hline Beta-blocker & $\begin{array}{l}\text { Beta-agonist, high-dose } \\
\text { glucagon }\end{array}$ & $\begin{array}{l}\text { Consider HD or } \\
\text { hemoperfusion only when } \\
\text { treatment with glucagon and } \\
\text { other pharmacotherapy fails }\end{array}$ & $\begin{array}{l}\text { Nadolol, sotalol, and atenolol are removed by HD. Acebutolol } \\
\text { is dialyzable. Propranolol, metoprolol, and timolol are not } \\
\text { removed by HD }\end{array}$ \\
\hline Barbiturates (MW $232 \mathrm{Da}$ ) & MDAC, urine alkalinization & HD or hemoperfusion & Phenobarbital is $50 \%$ protein bound, but VD is only $0.5 \mathrm{~L} / \mathrm{kg}$ \\
\hline $\begin{array}{l}\text { Ethylene glycol MW } 62 \\
\text { Da) }\end{array}$ & $\begin{array}{l}\text { Management of acidosis with } \\
\text { soda bicarbonate. Antidote } \\
\text { - ethanol or fomepizole. } \\
\text { Judicious intravenous fluids, } \\
\text { pyridoxine, thiamine }\end{array}$ & $\mathrm{HD}$ & $\begin{array}{l}\mathrm{HD} \text { until acidosis has resolved and level }<20 \mathrm{mg} / \mathrm{dl} \text {. Repeat } \\
\text { dialysis may be needed due to rebound elevation due to } \\
\text { redistribution }\end{array}$ \\
\hline Methanol (MW $32 \mathrm{Da})$ & $\begin{array}{l}\text { Sodabicarbonate. Antidote - } \\
\text { ethanol or fomepizole }\end{array}$ & $\mathrm{HD}$ & $\begin{array}{l}\text { HD will be continued until the acid is corrected and serum } \\
\text { methanol }<20 \mathrm{mg} / \mathrm{dl}\end{array}$ \\
\hline Isopropanol (MW $60 \mathrm{Da})$ & $\begin{array}{l}\text { Correction of hypotension } \\
\text { and hypoglycemia }\end{array}$ & $\begin{array}{l}\text { HD if isopropanol level } \\
>40 \mathrm{mg} / \mathrm{dl} \text {, neurological } \\
\text { depression, renal failure, or } \\
\text { hypotension }\end{array}$ & $\begin{array}{l}\text { High serum osmolal gap without acidosis in association with } \\
\text { increased urinary or serum acetone level is highly suggestive } \\
\text { of isopropanol poisoning }\end{array}$ \\
\hline Mushroom poisoning & $\begin{array}{l}\text { Activated charcoal, } \\
\text { silibinium, referral to a } \\
\text { poison center/liver transplant } \\
\text { center }\end{array}$ & $\begin{array}{l}\text { HD or hemoperfusion - } \\
\text { some survival benefits }\end{array}$ & Plasmapheresis - experimental treatment option \\
\hline $\begin{array}{l}\text { Tricyclic antidepressants/ } \\
\text { phenothiazines }\end{array}$ & $\begin{array}{l}\text { Supportive treatment } \\
\text { including bicarbonate } \\
\text { treatment }\end{array}$ & HD or hemoperfusion & $\begin{array}{l}\text { Large VD and highly protein bound. So, the total amount } \\
\text { removed by HD/hemoperfusion is very small }\end{array}$ \\
\hline Phenytoin & Stop the drug & HD or hemoperfusion & $\begin{array}{l}90 \% \text { protein bound and VD of } 0.64 \mathrm{~L} / \mathrm{kg} \text {. Despite high protein } \\
\text { binding, it is removed moderately well by } \mathrm{HD} / \text { hemoperfusion }\end{array}$ \\
\hline $\begin{array}{l}\text { Sodium valproate (MW } \\
166 \mathrm{Da})\end{array}$ & Stop the drug & $\begin{array}{l}\text { High-flux HD with or } \\
\text { without hemoperfusion }\end{array}$ & $\begin{array}{l}\text { Small VD, metabolized by the liver and has significant } \\
\text { protein binding }\end{array}$ \\
\hline $\begin{array}{l}\text { Carbamazepine (MW } \\
180 \mathrm{Da})\end{array}$ & Stop the drug & $\begin{array}{l}\text { Hemoperfusion for severe } \\
\text { intoxication }\end{array}$ & High-flux HD reported having good results \\
\hline Dabigatran & Stop the drug & $\begin{array}{l}\text { HD } \\
\text { Continuous venovenous } \\
\text { hemodiafiltration may be } \\
\text { useful in severe cases }\end{array}$ & $\begin{array}{l}\text { HD kinetics seem to follow first-order elimination during } \\
\text { dialysis }\end{array}$ \\
\hline
\end{tabular}

MDAC: Multiple dose-activated charcoal; MW: Molecular weight; HD: Hemodialysis; VD: Volume of distribution

with symptoms or with renal insufficiency, or when levels are expected to rise following recent massive ingestion. Due to rebound following hemodialysis, repeated dialysis sessions may be required until serum Li levels remain below $1.0 \mathrm{mmol} / \mathrm{L}$ for 6-8 h after dialysis. ${ }^{[49]}$ Hemodialysis has a minimal role in the treatment of beta-blocker overdose and is effective only 
with hydrophilic, minimally protein-bound beta-blockers such as atenolol. ${ }^{[50]}$ Nadolol, sotalol, acebutolol, and atenolol are reportedly removed by hemodialysis, but drugs such as propranolol, metoprolol, and timolol are not. CRRT can be used if the patient is unable to tolerate traditional hemodialysis due to pronounced hypotension.

In severe ethylene glycol or methanol poisoning, hemodialysis should be initiated as early as possible if any one of the following is present: severe acidosis $(\mathrm{pH}<7.25-7.30)$, renal failure, visual signs or symptoms, deteriorating vital signs despite intensive support care, or ethylene glycol or methanol levels $>50 \mathrm{mg} / \mathrm{dl}$ unless fomepizole is being administered and the patient is asymptomatic with a normal $\mathrm{pH} .{ }^{[51,52]}$ Theophylline is well adsorbed by charcoal and so activated charcoal should be used in significant poisoning even with IV theophylline overdose. Hemoperfusion or high-efficiency hemodialysis is indicated if vomiting prevents the use of activated charcoal, or it can be used in addition in patients with seizures, hypotension, or arrhythmia. In acute intoxication with levels above $100 \mathrm{mg} / \mathrm{L}$ and chronic toxicity with levels above $60 \mathrm{mg} / \mathrm{L}$, hemodialysis/hemoperfusion should be considered. ${ }^{[53]}$ Simultaneous hemodialysis and charcoal hemoperfusion should be considered in cases of extreme theophylline intoxication. ${ }^{[54]}$ Preferred ECTRs and initial management in case of poisoning due to some important selected agents are as summarized in Table 5.

\section{Conclusion}

Poisoning is a medical emergency and, in severe cases, extracorporeal treatments may be urgently required to prevent or reverse major toxicity. The different options include IHD, intermittent HF, HDF, CRRT, hemoperfusion, TPE, exchange transfusion, and PD. Characteristics of poison and different modalities of ECTRs may differ. EXTRIP recommendations are based on low-quality evidence but are the best guidance till now. With high-quality data, evolving epidemiology, and newer treatments, the existing recommendations may evolve.

\section{Financial support and sponsorship}

Nil.

\section{Conflicts of interest}

There are no conflicts of interest.

\section{References}

1. Mowry JB, Spyker DA, Cantilena LR Jr., Bailey JE, Ford M. 2012 Annual Report of the American Association of poison control centers' national poison data system (NPDS): $30^{\text {th }}$ annual report. Clin Toxicol (Phila) 2013;51:949-1229.

2. Abel JJ, Rowntree LG, Turner BB. On the removal of diffusable substances from the circulating blood by means of dialysis. Transactions of the Association of American Physicians, 1913. Transfus Sci 1990;11:164-5.

3. Lavergne V, Nolin TD, Hoffman RS, Roberts D, Gosselin S, Goldfarb DS, et al. The EXTRIP (EXtracorporeal TReatments in poisoning) workgroup: Guideline methodology. Clin Toxicol (Phila)
2012;50:403-13.

4. Hauk M, Kuhlmann MK, Riegel W, Köhler H. In vivo effects of dialysate flow rate on $\mathrm{Kt} / \mathrm{V}$ in maintenance hemodialysis patients. Am J Kidney Dis 2000;35:105-11.

5. Leypoldt JK, Cheung AK. Removal of high-molecular-weight solutes during high-efficiency and high-flux haemodialysis. Nephrol Dial Transplant 1996;11:329-35.

6. Brunet S, Leblanc M, Geadah D, Parent D, Courteau S, Cardinal J, et al. Diffusive and convective solute clearances during continuous renal replacement therapy at various dialysate and ultrafiltration flow rates. Am J Kidney Dis 1999;34:486-92.

7. Gong D, Ji D, Xie H, Xu B, Liu Y, Li L, et al. The effects of dialysate and ultrafiltration flow rate on solute clearance during continuous renal replacement therapy. Zhonghua Nei Ke Za Zhi 2001;40:183-6.

8. Powers KM, Wilkowski MJ, Helmandollar AW, Koenig KG, Bolton WK. Improved urea reduction ratio and $\mathrm{Kt} / \mathrm{V}$ in large hemodialysis patients using two dialyzers in parallel. Am J Kidney Dis 2000;35:266-74.

9. Churchwell MD, Pasko DA, Smoyer WE, Mueller BA. Enhanced clearance of highly protein-bound drugs by albumin-supplemented dialysate during modeled continuous hemodialysis. Nephrol Dial Transplant 2009;24:231-8.

10. Kan G, Jenkins I, Rangan G, Woodroffe A, Rhodes H, Joyce D, et al. Continuous haemodiafiltration compared with intermittent haemodialysis in the treatment of methanol poisoning. Nephrol Dial Transplant 2003;18:2665-7.

11. Wizemann V, Kulz M, Teichert F, Nederlof B. Efficacy of haemodiafiltration. Nephrol Dial Transplant 2001;16:27-30.

12. Colussi G, Frattini G. Quantitative analysis of convective dose in hemofiltration and hemodiafiltration: "predilution" vs. "postdilution" reinfusion. Hemodial Int 2007;11:76-85.

13. Pellicano R, Polkinghorne KR, Kerr PG. Reduction in beta2-microglobulin with super-flux versus high-flux dialysis membranes: Results of a 6-week, randomized, double-blind, crossover trial. Am J Kidney Dis 2008;52:93-101.

14. Ward RA. Protein-leaking membranes for hemodialysis: A new class of membranes in search of an application? J Am Soc Nephrol 2005; 16:2421-30

15. Hazouard E, Ferrandiere M, Rateau H, Doucet O, Perrotin D, Legras A. Continuous veno-venous haemofiltration versus continuous venovenous hemodialysis in severe lithium self-poisoning: A toxicokinetics study in an intensive care unit. Nephrol Dial Transplant 1999;14:1605-6.

16. Lornoy W, De Meester J, Becaus I, Billiouw JM, Van Malderen PA, Van Pottelberge M, et al. Impact of convective flow on phosphorus removal in maintenance hemodialysis patients. J Ren Nutr 2006;16:47-53.

17. Roberts DM, Yates C, Megarbane B, Winchester JF, Maclaren R, Gosselin S, et al. Recommendations for the role of extracorporeal treatments in the management of acute methanol poisoning: A systematic review and consensus statement. Crit Care Med 2015;43:461-72.

18. Liao Z, Zhang W, Hardy PA, Poh CK, Huang Z, Kraus MA, et al. Kinetic comparison of different acute dialysis therapies. Artif Organs 2003;27:802-7.

19. Amdisen A. Serum level monitoring and clinical pharmacokinetics of lithium. Clin Pharmacokinet 1977;2:73-92.

20. Goodman JW, Goldfarb DS. The role of continuous renal replacement therapy in the treatment of poisoning. Semin Dial 2006;19:402-7.

21. Yamashita AC. Mechanisms of solute and fluid removal in hemodiafiltration. Contrib Nephrol 2007;158:50-6.

22. Ghannoum M, Bouchard J, Nolin TD, Ouellet G, Roberts DM. Hemoperfusion for the treatment of poisoning: Technology, determinants of poison clearance, and application in clinical practice. Semin Dial 2014;27:350-61.

23. Rahman MH, Haqqie SS, McGoldrick MD. Acute hemolysis with acute renal failure in a patient with valproic acid poisoning treated with charcoal hemoperfusion. Hemodial Int 2006;10:256-9.

24. Falkenhagen D, Gottschall S, Esther G, Courtney JM, Klinkmann H. In vitro assessment of charcoal and resin hemoadsorbents. Contrib Nephrol 1982;29:23-33.

25. Mydlík M, Derzsiová K, Bucek J, Horký K, Jarcuska J, Takác M, et al. Use of charcoal haemoperfusion in 55 acute poisonings. Life Support 
Syst 1983;1 Suppl 1:53-6.

26. Szczepiorkowski ZM, Winters JL, Bandarenko N, Kim HC, Linenberger ML, Marques MB, et al. Guidelines on the use of therapeutic apheresis in clinical practice - Evidence-based approach from the apheresis applications committee of the American Society for Apheresis. J Clin Apher 2010;25:83-177.

27. Hastings D, Patel B, Torloni AS, Mookadam F, Betcher J, Moss A, et al. Plasmapheresis therapy for rare but potentially fatal reaction to rituximab. J Clin Apher 2009;24:28-31.

28. Jones JS, Dougherty J. Current status of plasmapheresis in toxicology. Ann Emerg Med 1986; 15:474-82.

29. Lee CS, Peterson JC, Marbury TC. Comparative pharmacokinetics of theophylline in peritoneal dialysis and hemodialysis. J Clin Pharmacol 1983;23:274-80.

30. Ouellet G, Bouchard J, Ghannoum M, Decker BS. Available extracorporeal treatments for poisoning: Overview and limitations. Semin Dial 2014;27:342-9.

31. Lionte C, Sorodoc L, Simionescu V. Successful treatment of an adult with amanita phalloides-induced fulminant liver failure with molecular adsorbent recirculating system (MARS). Rom J Gastroenterol 2005; 14:267-71.

32. Ghannoum M, Hoffman RS, Gosselin S, Nolin TD, Lavergne V, Roberts DM, et al. Use of extracorporeal treatments in the management of poisonings. Kidney Int 2018;94:682-8.

33. Wolley M, Jardine M, Hutchison CA. Exploring the clinical relevance of providing increased removal of large middle molecules. Clin J Am Soc Nephrol 2018;13:805-14.

34. Kirsch AH, Lyko R, Nilsson LG, Beck W, Amdahl M, Lechner P, et al. Performance of hemodialysis with novel medium cut-off dialyzers. Nephrol Dial Transplant 2017;32:165-72.

35. Lee S, Johnson D, Klein J, Eppler J. Protein binding of acetylsalicylic acid and salicylic acid in porcine and human serum. Vet Hum Toxicol 1995;37:224-5.

36. Calello DP, Liu KD, Wiegand TJ, Roberts DM, Lavergne V, Gosselin S, et al. Extracorporeal treatment for metformin poisoning: Systematic review and recommendations from the extracorporeal treatments in poisoning workgroup. Crit Care Med 2015;43:1716-30.

37. Ghannoum M, Lavergne V, Gosselin S, Mowry JB, Hoegberg LC, Yarema M, et al. Practice trends in the use of extracorporeal treatments for poisoning in four countries. Semin Dial 2016;29:71-80.

38. Lavergne V, Hoffman RS, Mowry JB, Cormier M, Gosselin S, Roberts DM, et al. Why are we still dialyzing overdoses to tricyclic antidepressants? A subanalysis of the NPDS database. Semin Dial 2016;29:403-9.

39. Bouchard J, Roberts DM, Roy L, Ouellet G, Decker BS, Mueller BA, et al. Principles and operational parameters to optimize poison removal with extracorporeal treatments. Semin Dial 2014;27:371-80.

40. Roberts DM, Buckley NA. Pharmacokinetic considerations in clinical toxicology: Clinical applications. Clin Pharmacokinet 2007;46:897-939.

41. Baird-Gunning J, Lea-Henry T, Hoegberg LCG, Gosselin S, Roberts DM. Lithium poisoning. J Intensive Care Med 2017;32:249-63.

42. Amdisen A, Skjoldborg H. Haemodialysis for lithium poisoning. Lancet 1969;2:213.

43. The Extracorporeal Treatments in Poisoning Workgroup. Available from: http://www.extrip-workgroup.org. [Last accessed on 2018 Dec 09].

44. Yates C, Galvao T, Sowinski KM, Mardini K, Botnaru T, Gosselin S, et al. Extracorporeal treatment for tricyclic antidepressant poisoning: Recommendations from the EXTRIP workgroup. Semin Dial 2014;27:381-9.

45. Mowry JB, Burdmann EA, Anseeuw K, Ayoub P, Ghannoum M, Hoffman RS, et al. Extracorporeal treatment for digoxin poisoning: Systematic review and recommendations from the EXTRIP workgroup. Clin Toxicol (Phila) 2016;54:103-14.

46. Palmer BF. Effectiveness of hemodialysis in the extracorporeal therapy of phenobarbital overdose. Am J Kidney Dis 2000;36:640-3.

47. Proudfoot AT, Stewart MS, Levitt T, Widdop B. Paraquat poisoning: Significance of plasma-paraquat concentrations. Lancet 1979;2:330-2.

48. Blanco-Ayala T, Andérica-Romero AC, Pedraza-Chaverri J. New insights into antioxidant strategies against paraquat toxicity. Free Radic Res 2014;48:623-40.

49. Leblanc $M$, Raymond $M$, Bonnardeaux A, Isenring P, Pichette V, Geadah $\mathrm{D}$, et al. Lithium poisoning treated by high-performance continuous arteriovenous and venovenous hemodiafiltration. Am J Kidney Dis 1996;27:365-72.

50. DeLima LG, Kharasch ED, Butler S. Successful pharmacologic treatment of massive atenolol overdose: Sequential hemodynamics and plasma atenolol concentrations. Anesthesiology 1995;83:204-7.

51. Barceloux DG, Bond GR, Krenzelok EP, Cooper H, Vale JA; American Academy of Clinical Toxicology Ad Hoc Committee on the Treatment Guidelines for Methanol Poisoning, et al. American Academy of Clinical Toxicology practice guidelines on the treatment of methanol poisoning. J Toxicol Clin Toxicol 2002;40:415-46.

52. Barceloux DG, Krenzelok EP, Olson K, Watson W. American Academy of clinical toxicology practice guidelines on the treatment of ethylene glycol poisoning. Ad hoc committee. J Toxicol Clin Toxicol 1999;37:537-60

53. Heath A, Knudsen K. Role of extracorporeal drug removal in acute theophylline poisoning. A review. Med Toxicol Adverse Drug Exp 1987;2:294-308

54. Hootkins R Sr., Lerman MJ, Thompson JR. Sequential and simultaneous "in series" hemodialysis and hemoperfusion in the management of theophylline intoxication. J Am Soc Nephrol 1990;1:923-6. 